\title{
PERSEPSI WISATAWAN JERMAN TERHADAP KUALITAS PELAYANAN PRAMUWISATA BERBAHASA JERMAN DI DENPASAR
}

\author{
Made Artajaya ${ }^{1 *}$, Kadek Novie Krisna Yanti² \\ 1,2Program Studi Bisnis Hospitaliti, Politeknik Pariwisata Bali \\ Jl. Dharmawangsa Kampial, Nusa Dua Bali \\ 1*)artajayamade10@gmail.com, ${ }^{2}$ kadeknov29@gmail.com \\ ${ }^{*}$ Corrensponding Author
}

\author{
\begin{tabular}{l|l|l} 
Received: Agustus, 2020 & Accepted: September, 2020 & Published: September, 2020
\end{tabular}
}

\begin{abstract}
The number of foreign tourists visiting Indonesia has increased every year. One of the services to meet the needs of tourists while traveling is a travel agency that serves travel servicesthe frequent occurrence of complaints to the service guide, it is necessary conducted research on the perception of German tourists towards the service quality of German speaking guide. This research will analyze the perception of German tourists as a service user of German speaking guide.The assessment will refer to the five dimensions of quality services, namely tangibles, reliability, responsiveness, assurance and empathy. Through this research will be known the aspects of good, which is necessary maintained, and bad aspects, which need to be fixed. For obtain data, applied techniques of documentation study, interview, observation, and distributing questionnaires to 100 German tourists as research samples. Data analysis method used is quantitative descriptive based on scale Likert. Based on the results of this study revealed that the respondents on average has an assessment and good perception with an average rating of 3,71 .
\end{abstract}

Keywords: tourism, travel agent, tourist perception, service quality, guides.

\begin{abstract}
Abstrak
Jumlah kunjungan wisatawan ke Indonesia mengalami peningkatan setiap tahunnya. Salah satu jasa untuk memenuhi kebutuhan wisatawan saat melakukan perjalanan wisata adalah biro perjalanan wisata. Sering terjadinya keluhan dari wisatawan Jerman terhadap pelayanan pramuwisata, maka perlu dilakukan penelitian tentang persepsi wisatawan Jerman terhadap kualitas pelayanan pramuwisata berbahasa Jerman. Penelitian ini akan menganalisis persepsi wisatawan Jerman selaku pengguna jasa pelayanan pramuwisata berbahasa Jerman. Penilaian yang dilakukan akan mengacu pada lima dimensi kualitas pelayanan, yakni bukti fisik (tangibles), kehandalan (reliability), daya tanggap (responsiveness), jaminan (assurance), dan empati (empathy). Untuk memperoleh data, digunakan teknik studi dokumentasi, wawancara, observasi, dan penyebaran kuesioner kepada 100 wisatawan Jerman sebagai sampel penelitian. Metode analisis data yang digunakan adalah deskriptif kuantitatif berdasar skala Likert. Berdasarkan hasil penelitian
\end{abstract}


Artajaya, Yanti

ini mengungkap bahwa responden rata-rata memiliki penilaian dan persepsi yang baik dengan nilai rata-rata 3,71.

Kata Kunci: pariwisata, biro perjalanan, persepsi wisatawan, kualitas pelayanan, pramuwisata.

\section{PENDAHULUAN}

Sektor pariwisata masih menjadi andalan bagi provinsi Bali. Berdasarkan dari data Badan Pusat Statistik Provinsi Bali pada tahun 2017 jumlah kunjungan wisatawan domestik maupun wisatawan asing yang berkunjung ke Bali terus mengalami peningkatan setiap tahun. Selain menarik wisatawan, Bali juga sukses menyelenggarakan berbagai pertemuan penting seperti konferensi tingkat tinggi (KTT) ASEAN (1976, 2003, dan 2011), United Nation Framework on Climate Change (UNFCC) (2007), AsiaPasific Economic Cooperation (APEC) (2013). Hal tersebut membuktikan dengan banyaknya wisatawan yang berkunjung ke Bali bukan hanya wisatawan domestik tetapi juga wisatawan asing yang dari tahun ke tahun mengalami peningkatan.

Tabel 1 : Jumlah Kunjungan Wisatawan Asing yang langsung ke Bali Tahun 2013 2017

[Sumber : Badan Pusat Statistik 2018 (data diolah)

\begin{tabular}{cccc}
\hline No. & Tahun & $\begin{array}{c}\text { Jumlah Kunjungan } \\
(\text { Orang })\end{array}$ & $\begin{array}{c}\text { Pertumbuhan } \\
(\%)\end{array}$ \\
\hline 1 & 2013 & 3.278 .598 & - \\
2 & 2014 & 3.766 .638 & 14,88 \\
3 & 2015 & 4.001 .835 & 6,24 \\
4 & 2016 & 4.927 .937 & 23,14 \\
5 & 2017 & 5.697 .739 & 15,62 \\
\hline
\end{tabular}

Berdasarkan tabel di atas oleh wisatawan seperti akomodasi, memberikan gambaran bahwa Bali transportasi yang memadai, daya tarik menjadi destinasi pariwisata yang wisata yang menarik dan dikelola dengan menarik. Pariwisata di Bali juga baik, sopan santun, serta pelayanan yang memperhatikan hal-hal yang dibutuhkan memuaskan.

Tabel 2 : Jumlah Wisatawan yang menggunakan jasa PT. Asian Trails Indonesia Tahun 2012 - 2017 [Sumber : PT. Asian Trails Indonesia 2018 (data diolah)]

\begin{tabular}{|c|c|c|c|c|c|c|c|}
\hline \multirow[t]{2}{*}{ No. } & \multirow{2}{*}{$\begin{array}{c}\text { Asal } \\
\text { Wisatawan }\end{array}$} & \multicolumn{5}{|c|}{ Tahun } & \multirow[t]{2}{*}{ Total } \\
\hline & & 2013 & 2014 & 2015 & 2016 & 2017 & \\
\hline 1 & Jerman & 40.041 & 33.309 & 39.703 & 41.012 & 39.365 & 193.430 \\
\hline 2 & Perancis & 4.537 & 3.728 & 2.848 & 2.443 & 2.919 & 16.475 \\
\hline 3 & Belanda & 875 & 954 & 730 & 723 & 642 & 3.924 \\
\hline \multicolumn{2}{|c|}{ Total Wisatawan } & 45.453 & 37.991 & 43.281 & 44.178 & 42.926 & 213.829 \\
\hline
\end{tabular}


Artajaya, Yanti

Pada tabel dapat dilihat bahwa wisatawan Jerman memiliki tingkat kunjungan tertinggi yaitu sebanyak 193.430 wisatawan. Sedangkan, Perancis ada di urutan kedua dengan jumlah kunjungan sebanyak 16.475 wisatawan, dan diurutan ketiga yaitu Belanda dengan jumlah wisatawan sebanyak 3.924. Namun dari banyaknya jumlah wisatawan Jerman yang menggunakan jasa PT. Asian Trails Indonesia terdapat berbagai keluhan yang terjadi dari wisatawan, sehingga jumlah wisatawan Jerman mengalami peningkatan dan penurunan jumlah kunjungan yang kurang stabil. Salah satu unsur terpenting dalam menarik minat wisatawan untuk berkunjung ke Bali adalah memberikan pelayanan yang berkualitas kepada wisatawan, Peran pramuwisata dalam memberikan pelayanan harus selalu diperhatikan, mengingat bahwa pramuwisatalah sebagai ujung tombak yang akan berhadapan langsung dengan wisatawan. Pramuwisata harus mampu memberikan informasi yang benar mengenai destinasi wisata atau daya tarik wisata yang dikunjungi wisatawan dengan menggunakan bahasa asing yang mudah dimengerti oleh wisatawan. Pramuwisata juga harus memberikan keramahtamahan serta rasa nyaman sehingga wisatawan berkeinginan menggunakan kembali jasa dari PT. Asian Trails Indonesia.

Tabel 3 : Data Keluhan Wisatawan Jerman Terhadap Pramuwisata Berbahasa Jerman di PT. Asian Trails Indonesia Tahun 2013 - 2017

\begin{tabular}{|c|c|}
\hline No. & Keluhan \\
\hline 1 & $\begin{array}{l}\text { Clients that he was friendly, however could hardly understand and communicate in } \\
\text { German or English }\end{array}$ \\
\hline 2 & $\begin{array}{l}\text { His German is good, easy to understand and he understand me as well. However, only } \\
\text { concern is his massage/healing practices, which could be disturbing for the clients. Need } \\
\text { to make sure he understands that the guiding is first priority }\end{array}$ \\
\hline 3 & $\begin{array}{l}\text { Our guide on the spot brought us to the hotel and did not have anything to do with us } \\
\text { except that she told us when we were going to Medan, then we sat together again in the } \\
\text { car (where she slept mostly) and on the day of departure, she came } 1 \text { hour late to the } \\
\text { hotel reception without letting us know }\end{array}$ \\
\hline 4 & $\begin{array}{l}\text { He is personally really shy which makes it hard for him to talk. He actually did not } \\
\text { understand me. I would only use him even for transfer if there is really no one else }\end{array}$ \\
\hline 5 & $\begin{array}{l}\text { His German is ok, but I have to repeat question a few times until he understood me. It's } \\
\text { fine for transfers, however till no I would not use him for more }\end{array}$ \\
\hline & $\begin{array}{l}\text { The time in between he used to speak in "Indonesian language" with the driver and they } \\
\text { had a lot of fun. } \\
\text { What we missed were information on the flora and fauna of Bali about the historv of }\end{array}$ \\
\hline 6 & $\begin{array}{l}\text { Bali, the infrastructure, school system, university, connections to the other islands, and } \\
\text { also more information on the different temples, when they were built, why, for which } \\
\text { exact reason. For the temples we received some of the information, but still it was a bit } \\
\text { too less for my personal feeling. }\end{array}$ \\
\hline 7 & $\begin{array}{l}\text { The Asian Trails transfer guide didn't provide any assistance (disappeared) upon } \\
\text { arrival. }\end{array}$ \\
\hline 8 & $\begin{array}{l}\text { At the airport, she went to the airport after the first security check-up, which meant she } \\
\text { was the first and we still had to wait for our belongings, without informing us that she } \\
\text { was already at the check-in check-out. We were standing around for a while and then } \\
\text { looked for the appropriate switch, where she stood. }\end{array}$ \\
\hline
\end{tabular}


Artajaya, Yanti

9 His German is quite basic, which makes it hard for him to understand. You have to speak really slow that he understands.

10 The guide is lack of sympathy behavior in handling the guest complaints.

Persepsi merupakan salah satu aspek psikologis yang penting bagi manusia dalam merespon kehadiran berbagai aspek dan gejala di sekitarnya. Persepsi berasal dari bahasa Inggris yaitu kata percepstion, yang diambil dari bahasa latinperception, yang berarti menerima atau mengambil. Dalam KBBI (Kamus Besar Bahasa Indonesia) persepsi berarti tanggapan langsung atas sesuatu.

Menurut Sarwono (2013:86) persepsi berlangsung saat seseorang menerima stimulus dari dunia luar yang ditangkap oleh organ-organ bantunya yang kemudian masuk ke dalam otak, didalamnya terjadi proses berpikir yang pada akhirnya terwujud dalam sebuah pemahaman. Pemahaman ini yang kurang lebih disebut persepsi. Sedangkan menurut Webster dalam Astuti (2016:34), persepsi adalah proses bagaimana stimuli-stimuli itu diseleksi, diorganisasi, dan interpretasikan. Persepsi (perception) dalam arti sempit adalah penglihatan, bagaimana cara seseorang melihat sesuatu, sedangkan dalam arti luas ialah pandangan atau pengertian, yaitu bagaimana seseorang memandang atau mengartikan sesuatu.

Dari beberapa pengertian di atas dapat disimpulkan bahwa persepsi adalah proses dimana seseorang menanggapi suatu informasi kemudian menyeleksi, mengatur dan menginterpretasikannya yang pada akhirnya terwujud sebuah pemahaman atau gambaran. Menurut The International Union of Office Travel Organization (IUOTO) dalam Suwena dan Widyatmaja (2010:36), wisatawan adalah setiap orang yang bertempat tinggal di suatu negara tanpa memandang kewarganegaraannya, berkunjung ke suatu tempat pada negara yang sama untuk jangka waktu lebih dari 24 jam yang tujuan perjalanannya dapat diklasifikasikan pada salah satu hal berikut:

1) Memanfaatkan waktu luang untuk berekreasi, liburan, kesehatan, pendidikan, keagamaan, dan olah raga.

2) Bisnis atau mengunjungi kaum keluarga.

Kesimpulan dari beberapa pengertian wisatawan di atas bahwa seseorang dapat dikatakan sebagai wisatawan apabila memiliki ciri-ciri sebagai berikut:

1) Perjalanan tersebut dilakukan lebih dari 24 jam

2) Perjalanan tersebut dilakukan untuk sementara waktu

3) Mereka yang melakukannya tidak bermaksud untuk mencari nafkah di tempat atau negara yang dikunjungi.

Berdasarkan penjelasan tersebut yang dimaksud dengan persepsi wisatawan adalah tanggapan dari wisatawan terhadap informasi yang diperoleh dan kemudian di seleksi sehingga akhirnya membentuk sebuah gambaran atau penilaian.

Menurut Walgito (2004:90) beberapa faktor yang berperan agar dapat terjadinya suatu persepsi yaitu: a)Objek atau stimulus yang dipersepsi. Objek dari luar diri seseorang baik berupa benda, kejadian, ataupun sikap dari orang lain biasanya merupakan sumber stimulus bagi seseorang; b)Alat indera, syaraf, dan pusat susunan syaraf. Melalui alat indera yang dimiliki seseorang, stimuli yang ada diterima oleh seseorang. Dengan syaraf sebagai pusat kesadaran, seseorang akan menginterpretasikan stimuli yang diterima. c) Perhatian Perhatian merupakan pemusatan atau konsentrasi dari seluruh aktifitas individu yang ditunjukan kepada sesuatu atau sekelompok objek. 


\subsection{Pengertian Pramuwisata}

Pengertian pramuwisata menurut Yoeti(2001:10), pramuwisata secara umum adalah seseorang yang dibayar untuk menemani wisatawan dalam perjalanan mengunjungi, melihat serta menyaksikan objek dan atraksi wisata sedangkan dari sudut pandang wisatawan, pramuwisata adalah seseorang yang bekerja pada suatu biro perjalanan atau suatu kantor pariwisata (Tourism Office) yang bertugas memberikan informasi, petunjuk dan advice secara langsungkepada wisatawan sebelum dan selama perjalanan berlangsung.

Menurut World Federation of Tour Guide Associationmendefinisikan Tourist guide atau pramuwisata sebagai:

"a person who guides visitors in the language of their choice and interprets the cultural and natural heritage of an area which person normally possesses an area-specific qualification usually issued and/or recognised by the appropriate authority"

Berdasarkan Keputusan Menteri Pariwisata, Pos dan Telekomunikasi Nomor KM. 82/PW. 102/MPPT-88 tentang Pramuwisata dan Pengatur Pariwisata, Pos dan Telekomunikasi, pramuwisata adalah seseorang yang bertugas memberikan bimbingan, penerangan, dan petunjuk tentang obyek wisata, serta membantu segala sesuatu yang diperlukan wisatawan.

\subsection{Pengertian Kualitas Pelayanan}

Menurut Kotler (2005:99) bahwa kualitas merupakan suatu kondisi dinamis yang berhubungan dengan produk, jasa, manusia, proses, dan lingkungan yang memenuhi atau melebihi harapan. Sedangkan Davis dalam Yamit (2004:8) membuat definisi yang lebih luas cakupannya yaitu kualitas merupakan suatu kondisi dinamis yang berhubungan dengan produk, jasa, manusia, proses, dan lingkungan yang memenuhi, atau yang melebihi harapan. Pendekatan yang dikemukakan Davis menegaskan bahwa kualitas bukan hanya menekankan pada aspek akhir yaitu produk dan jasa tetapi juga menyangkut kualitas manusia, kualitas proses, dan kualitas lingkungan. Sangatlah mustahil menghasilkan produk dan jasa yang berkualitas tanpa melalui manusia dan produk yang berkualitas.

Gaspersz (2005:5) dalam bukunya Total Quality Management mengatakan bahwa pada dasarnya kualitas mengacu pada pengertian pokok berikut:

1) Kualitas terdiri dari sejumlah keistimewaan produk, maupun keistimewaan atraktif yang memenuhi keinginan pelanggan dan dengan demikian memberikan kepuasan terhadap penggunaan produk itu.

2) Kualitas terdiri dari segala sesuatu yang bebas dari kekurangan atau kerusakan.

Sedangkan menurut Wykoff dalam Tjiptono (2006:59) kualitas adalah tingkat keunggulan yang diharapkan dan pengendalian atas tingkat keunggulan tersebut untuk memenuhi dan melebihi keinginan serta harapan pelanggan. Dari beberapa pengertian di dapat disimpulkan bahwa kualitas merupakan kondisi yang berhubungan dengan produk, jasa, manusia, atau proses yang memenuhi harapan konsumen (wisatawan).

Parasuraman, Zeithmal, dan Berry dalam Suryadana dan Vanny Octavia (2015:127) mengemukakan sebuah teknik untuk mengukur kualitas dan pelayanan yang disebut dengan Servqual. Teknik Servqual menggunakan lima dimensi individu untuk mengukur harapan dan persepsi dan wisatawan, yaitu:

1) Bukti Langsung (Tangible), fasilitas fisik dari hotel dan organisasi travel, perlengkapan dan penampilan karyawan.

2) Keandalan (Reliability), kemampuan hotel dan organisasi travel untuk menujukkan pelayanan yang dapat kepercayaan yang akurat.

3) Daya Tanggap (Responsiveness), keinginan karyawan untuk 
membantu wisatawan dan menyediakan pelayanan yang cepat.

4) Jaminan dan Kepastian (Assurance), pengetahuan dan courtesy dari wisatawan dan kemampuan mereka untuk memberikan kepercayaan dan keyakinan.

5) Empati (Empathy), tingkat perhatian (care) secara individu yang disediakan karyawan hotel dan organisasi perjalanan kepada wisatawan.

Menurut Yoeti (2001:29) ruang lingkup kegiatan usaha Biro Perjalanan Wisata yaitu, membuat, menjual, dan menyelenggarakan paket wisata, mengurus, dan melayani kebutuhan jasa angkutan bagi perorangan dan atau kelompok orang yang diurusnya, melayani pemesanan akomodasi, restoran dan sarana wisata lainnya,mengurus dokumen perjalanan, menyelenggarakan panduan perjalanan wisata, melayanai penyelenggaraan konvensi.

Muljadi dan Warman (2014:60) menyatakan bahwa Biro Perjalanan Wisata merupakan usaha pariwisata yang berbentuk badan usaha. Bentuk badan usahanya dapat berupa perseroan terbatas atau koperasi. Persyaratan utama dalam menjalankan usaha ini adalah tersedianya tenaga profesional dalam jumlah dan kualitas yang memadai serta dimilikinya kantor tetap yang memenuhi syarat sesuai peraturan. Kegiatan Biro Perjalanan Wisata, meliputi:

1) Perencanaan dan pengawasan komponen - komponen perjalanan wisata yang meliputi sarana wisata, objek dan daya tarik wisata dan pariwisata lainnya, terutama yang terdapat di wilayah Republik Indonesia dalam bentuk paket wisata.

2) Penyelenggaraan dan penjualan paket wisata dengan cara menyalurkan melalui agen perjalanan wisata dan/ atau penjualannya langsung kepada wisatawan atau konsumen.
3) Penyediaan layanan pramuwisata yang berhubungan dengan paket wisata yang dijual.

4) Penyediaan layanan angkutan wisata.

5) Pemesanan akomodasi, restoran tempat konvensi, dan tiket pertunjukan seni budaya serta kunjungan ke objek dan daya tarik wisata.

6) Pengurusan dokumen perjalanan berupa paspor dan visa atau dokumen lain yang dipersamakan.

7) Penyelenggaraan perjalanan ibadah agama.

8) Penyelenggaraan perjalanan insentif. Menurut Undang - Undang Nomor 10 tahun 2009 tentang Kepariwisataan, menetapkan bahwa untuk dapat menyelenggarakan usaha pariwisata atau Biro Perjalanan Wisata, pengusaha pariwisata wajib mendaftarkan usahanya terlebih dahulu kepada Pemerintah atau Pemerintah Daerah. Ketentuan lebih lanjut mengenai tata cara pendaftaran sebagaimana diatur dengan Peraturan Menteri (http://www.kemenpar.go.id/ diakses 24 April 2018).

\section{METODE PENELITIAN}

Penelitian ini merupakan penelitian di bidang pariwisata yang dilakukan dengan pendekatan kuantitatif. Data primer yang dianalisis didapat dari penyebaran kuestioner kepada serratus limabelas responden. Dari jumlah tersebut, sebanyak 100 orang mengisi dan mengembalikan kuestioner dengan lengkap dan layak untuk dianalisis selanjutnya.

Responden yang menjadi sumber primer dari pengumpulan data kuantitatif merupakan wisatawan Jerman yang menggunakan layanan pemandu wisata berbahasa Jerman pada PT Asians Trail Indonesia. Pemilihan responden tersebut dilakukan berdasarkan pendekatan incidental yaitu bahwa wisatawan yang menjadi responden adalah mereka yang ditemui pada saat pengumpulan data.

Instrumen yang dipergunakan untuk mengumpulkan data primer berupa 
Artajaya, Yanti

kuesioner dengan Skala Likert dengan 5 alternatif pilihan respon, yaitu Sangat

\section{HASIL DAN PEMBAHASAN}

\subsection{Karakteristik Wisatawan}

Hasil penyebaran kuesioner kepada responden yaitu wisatawan Jerman yang menggunakan jasa PT. Asian Trails Indonesia berupa pemandu wisata berbahasa Jerman terdiri dari 42\%
Buruk, Buruk, Cukup, Baik, dan Sangat Baik.

Wanita dan 58\% Pria. Hal ini menunjukan bahwa dari segi jenis kelamin responden wanita dan pria hampir seimbang. Perbandingan responden dari segi jenis kelamin dapat dilihat pada gambar 1 .

Gambar 1 : Wisatawan Jerman Berdasarkan Jenis Kelamin

[Sumber : Kuesioner, Tahun 2018]

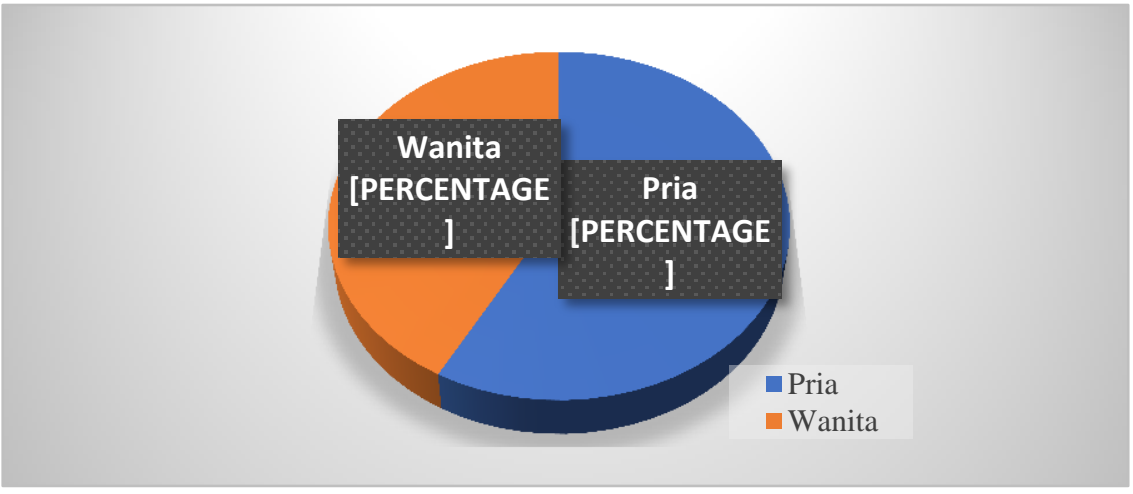

Berdasarkan usia, responden dikelompokan kedalam rentangan sebagai berikut : umur 20 -29 tahun sebanyak 23\%, umur 30-39 tahun sebanyak 34\%, umur 40-49 tahun sebanyak 31\%, umur 50-59 sebanyak
8\% dan umur diatas 59 tahun sebanyak $4 \%$. Hal ini menunjukan bahwa sebagian besar responden berada pada usian antara 20-49 tahun yaitu 88\%. Karakteristik responden berdasarkan usia dapat dilihat pada gambar 2 .

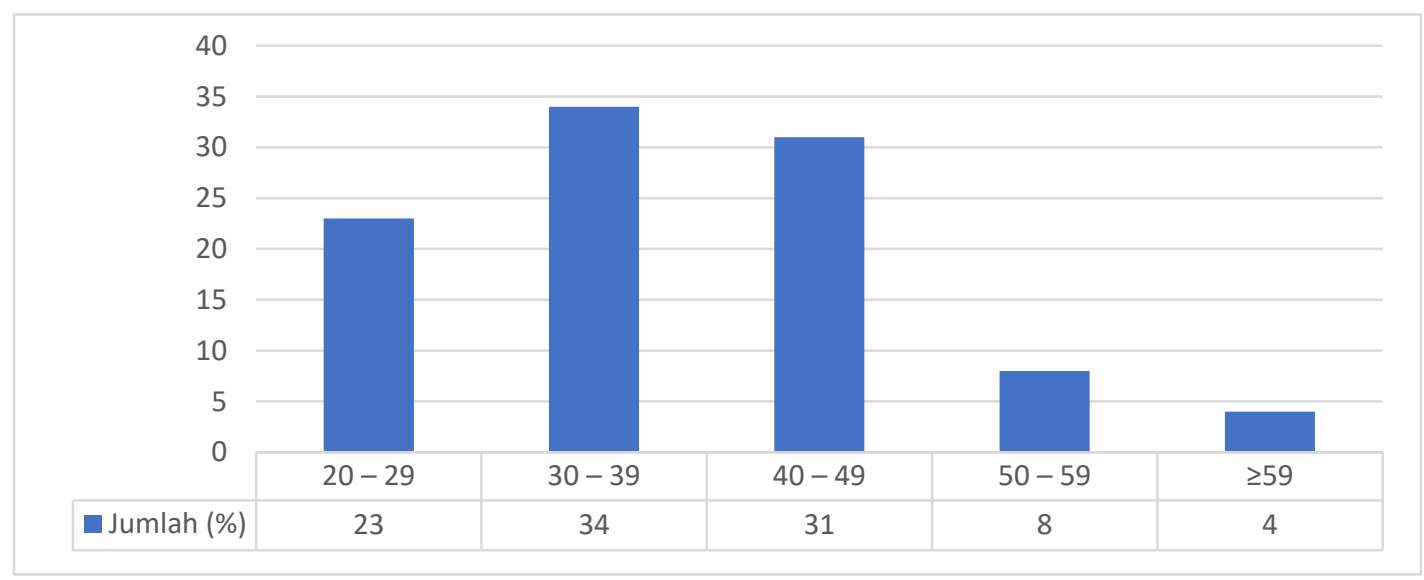

Gambar 2 : Karakteristik Wisatawan Jerman Berdasarkan Usia

[Sumber : Kuesioner, Tahun 2018] 
Artajaya, Yanti

Karakteristik responden berdasarkan pekerjaan dapat dilihat pada gambar 3. Para responden dalam penelitian ini terdiri dari pengusaha

(29\%), karyawan swasta (25\%), pensiunan (6\%), pelajar/mahasiswa (17\%), pegawai negeri (12\%), dan lainnya

Pelajar $\square$ Pegawai Negeri $\square$ Pengusaha $\square$ Karyawan Swasta $\square$ Pensiunan $\square$ Lainnya

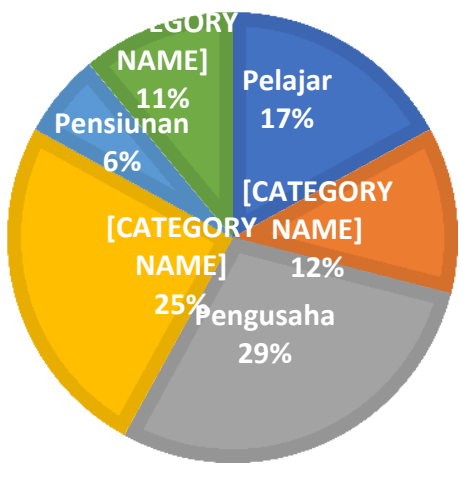

Gambar 3 : Karakteristik Wisatawan Jerman Berdasarkan Pekerjaan

[Sumber : Kuesioner, Tahun 2018]

3.2 Persepsi Wisatawan Jerman Terhadap Kualitas Pelayanan Pramuwisata Berbahasa Jerman di PT. Asian Trails Indonesia Dimensi Tangible

Penilaian wisatawan Jerman terhadap dimensi kualitas pelayanan tangible dihitung dengan mencari rata- ratanilai yang telah didapat dari tanggapan wisatawan Jerman melalui kuesioner. Adapun hasil dari penyebaran 100 kuesioner persepsi wisatawan Jerman yang berlibur di Bali dan menggunakan jasa PT. Asian Trails Indonesia terhadap dimensi tangible, pada tabel sebagai berikut :

Tabel 4 : Hasil Penyebaran 100 Kuesioner Mengunakan Dimensi Tangible

[Sumber : Hasil Pengolahan Data Penelitian, 2018]

\begin{tabular}{|c|c|c|c|c|c|c|c|c|c|c|c|c|c|c|c|}
\hline & \multirow[t]{3}{*}{ Indikator } & \multicolumn{2}{|c|}{$\begin{array}{l}\text { Sangat } \\
\text { Buruk }\end{array}$} & \multicolumn{2}{|c|}{ Buruk } & \multicolumn{2}{|c|}{ Cukup } & \multicolumn{2}{|c|}{ Baik } & \multicolumn{2}{|c|}{$\begin{array}{l}\text { Sangat } \\
\text { Baik }\end{array}$} & \multirow[t]{3}{*}{$\mathrm{N}$} & \multirow[t]{3}{*}{$\Sigma \mathrm{n} . \mathrm{B}$} & \multirow[t]{3}{*}{$\chi$} & \multirow[t]{3}{*}{ Kategor } \\
\hline & & \multicolumn{2}{|c|}{ [1] } & \multicolumn{2}{|c|}{ [2] } & \multicolumn{2}{|c|}{ [3] } & \multicolumn{2}{|c|}{ [4] } & \multicolumn{2}{|c|}{ [5] } & & & & \\
\hline & & $\mathrm{n}$ & n.B & $\mathrm{n}$ & n.B & $\mathrm{n}$ & n.B & $\mathrm{N}$ & n.B & $\mathrm{n}$ & n.B & & & & \\
\hline 1 & $\begin{array}{l}\text { Kebersihan } \\
\text { seragam } \\
\text { pramuwisata }\end{array}$ & 0 & 0 & 2 & 4 & 19 & 57 & 35 & 140 & 44 & 220 & & 421 & 4,21 & $\begin{array}{l}\text { Sangat } \\
\text { Baik }\end{array}$ \\
\hline 2 & $\begin{array}{l}\text { Penampilan } \\
\text { pramuwisata }\end{array}$ & 0 & 0 & 4 & 8 & 22 & 66 & 47 & 188 & 27 & 135 & 100 & 397 & 3,97 & Baik \\
\hline 3 & $\begin{array}{l}\text { Kebersihan } \\
\text { Kendaraan }\end{array}$ & 0 & 0 & 1 & 2 & 27 & 81 & 51 & 204 & 21 & 105 & & 392 & 3,92 & Baik \\
\hline 4 & $\begin{array}{l}\text { Kendaraan dalam } \\
\text { kondisi baik }\end{array}$ & 0 & 0 & 4 & 8 & 30 & 90 & 42 & 168 & 24 & 120 & & 386 & 3,86 & Baik \\
\hline
\end{tabular}




\section{Nilai Rata-Rata}

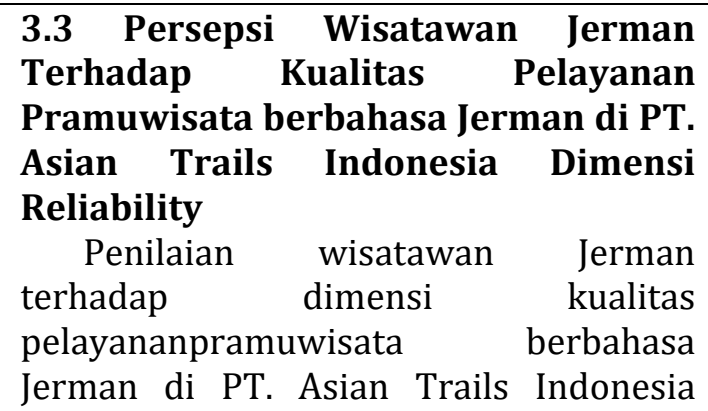

dimensi reliability, dihitung dengan mencari rata-ratanilai yang telah didapat dari tanggapan wisatawan Jerman melalui kuesioner. Adapun hasil dari penyebaran 100 kuesioner persepsi wisatawan Jerman yang berlibur di Bali dan menggunakan jasa PT. Asian Trails Indonesia terhadap dimensi reliability, pada tabel sebagai berikut:

Tabel 5 : Hasil Penyebaran 100 Kuesioner Mengunakan Dimensi Reliability

[Sumber : Hasil Pengolahan Data Penelitian, 2018]

\begin{tabular}{|c|c|c|c|c|c|c|c|c|c|c|c|c|c|c|c|}
\hline & \multirow{3}{*}{ Indikator } & \multirow{2}{*}{\multicolumn{2}{|c|}{$\begin{array}{c}\text { Sangat } \\
\text { Buruk } \\
{[1]}\end{array}$}} & \multicolumn{2}{|c|}{ Buruk } & \multicolumn{2}{|c|}{ Cukup } & \multicolumn{2}{|c|}{ Baik } & \multicolumn{2}{|c|}{$\begin{array}{l}\text { Sangat } \\
\text { Baik }\end{array}$} & \multirow{3}{*}{$\mathrm{N}$} & \multirow{3}{*}{$\Sigma \mathrm{n} \cdot \mathrm{B}$} & \multirow{3}{*}{$\chi$} & \multirow{3}{*}{ Kategor } \\
\hline & & & & \multicolumn{2}{|c|}{ [2] } & \multicolumn{2}{|c|}{ [3] } & \multicolumn{2}{|c|}{ [4] } & \multicolumn{2}{|c|}{ [5] } & & & & \\
\hline & & $\mathrm{n}$ & n.B & $\mathrm{n}$ & n. B & $\mathrm{N}$ & n.B & $\mathrm{n}$ & n. B & $\mathrm{n}$ & n.B & & & & \\
\hline 1 & $\begin{array}{l}\text { Pramuwisata sangat } \\
\text { membantu } \\
\text { Pramuwisata } \\
\text { memberikan }\end{array}$ & 0 & 0 & 8 & 16 & 40 & 120 & 36 & 144 & 16 & 80 & & 360 & 3,60 & Baik \\
\hline 2 & $\begin{array}{l}\text { informasi yang } \\
\text { dibutuhkan tentang } \\
\text { daya tarik wisata }\end{array}$ & 0 & 0 & 2 & 4 & 17 & 51 & 44 & 176 & 37 & 185 & 100 & 416 & 4,16 & Baik \\
\hline 3 & $\begin{array}{l}\text { Pramuwisata dapat } \\
\text { berbahasa Jerman } \\
\text { dengan lancer }\end{array}$ & 0 & 0 & 15 & 30 & 41 & 123 & 32 & 128 & 12 & 60 & & 341 & 3,41 & Baik \\
\hline 4 & $\begin{array}{l}\text { Kemampuan untuk } \\
\text { menangani masalah }\end{array}$ & 0 & 0 & 10 & 20 & 38 & 114 & 42 & 168 & 10 & 50 & & 352 & 3,52 & Baik \\
\hline & & & & & Nila & & & & & & & & & 3,67 & Baik \\
\hline
\end{tabular}

\subsection{Persepsi Wisatawan Jerman} Terhadap Kualitas Pelayanan Pramuwisata berbahasa Jerman di PT. Asian Trails Indonesia Dimensi Responsiveness

Penilaian wisatawan Jerman terhadap dimensi kualitas pelayananpramuwisata berbahasa Jerman di PT. Asian Trails Indonesia dimensi responsiveness, dihitung dengan mencari rata-ratanilai yang telah didapat dari tanggapan wisatawan Jerman melalui kuesioner. Adapun hasil dari penyebaran 100 kuesioner persepsi wisatawan Jerman yang berlibur di Bali dan menggunakan jasa PT. Asian Trails Indonesia terhadap dimensi responsiveness, pada tabel sebagai berikut:

Tabel 5 : Hasil Penyebaran 100 Kuesioner Mengunakan Dimensi Responsiveness [Sumber : Hasil Pengolahan Data Penelitian, 2018]

\begin{tabular}{|c|c|c|c|c|c|c|c|c|c|c|c|c|c|c|c|}
\hline & \multirow{3}{*}{ Indikator } & \multirow{2}{*}{\multicolumn{2}{|c|}{$\begin{array}{c}\text { Sangat } \\
\text { Buruk }\end{array}$}} & \multicolumn{2}{|c|}{ Buruk } & \multicolumn{2}{|c|}{ Cukup } & \multicolumn{2}{|c|}{ Baik } & & & \multirow{3}{*}{$\mathrm{N}$} & \multirow{3}{*}{$\Sigma \mathrm{n} . \mathrm{B}$} & \multirow{3}{*}{$\chi$} & \multirow{3}{*}{ Kategor } \\
\hline & & & & & & & & & & & & & & & \\
\hline & & $\mathrm{n}$ & n.B & $\mathrm{n}$ & n.B & $\mathrm{n}$ & n.B & $\mathrm{n}$ & n.B & $\mathrm{n}$ & n.B & & & & \\
\hline 1 & $\begin{array}{l}\text { Pramuwisata } \\
\text { bersedia membantu }\end{array}$ & 0 & 0 & 7 & 14 & 42 & 126 & 37 & 148 & 14 & 70 & 100 & 358 & 3,58 & Baik \\
\hline
\end{tabular}




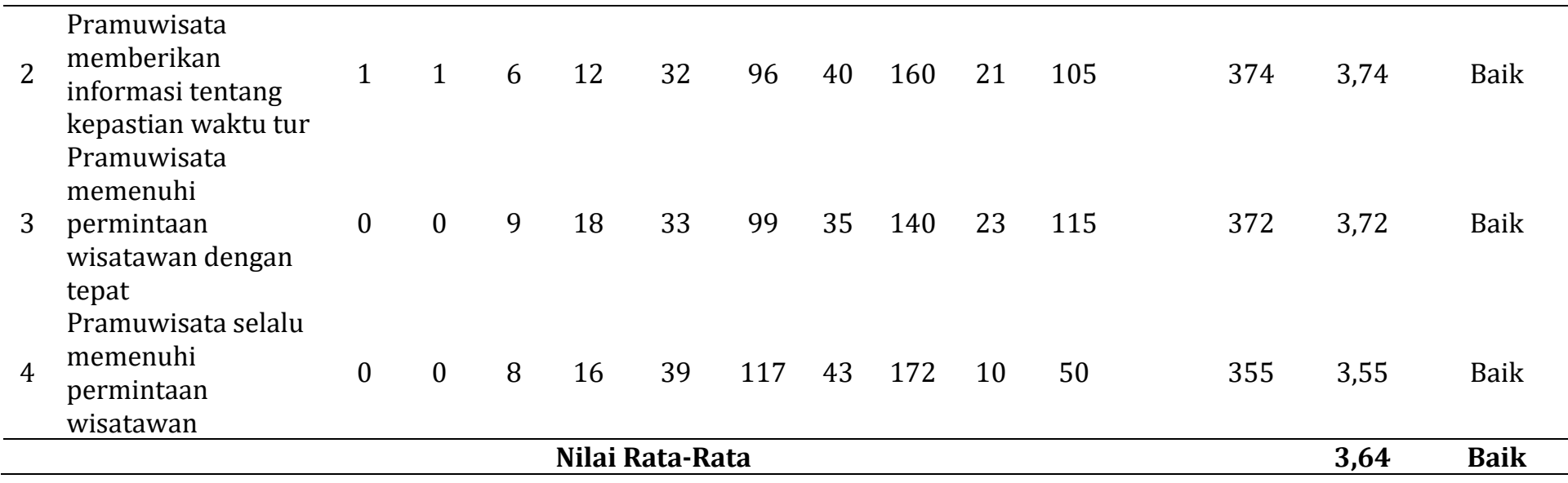

3.5 Persepsi Wisatawan Jerman Terhadap Kualitas Pelayanan Pramuwisata berbahasa Jerman di PT. Asian Trails Indonesia Dimensi Assurance

Penilaian wisatawan Jerman terhadap dimensi kualitas pelayananpramuwisata berbahasa Jerman di PT. Asian Trails Indonesia dimensi assurance, dihitung dengan mencari rata-rata nilai yang telah didapat dari tanggapan wisatawan Jerman melalui kuesioner. Adapun hasil dari penyebaran 100 kuesioner persepsi wisatawan Jerman yang berlibur di Bali dan menggunakan jasa PT. Asian Trails Indonesia terhadap dimensi assurance, pada tabel sebagai berikut:

Tabel 6 : Hasil Penyebaran 100 Kuesioner Mengunakan Dimensi assurance

[Sumber : Hasil Pengolahan Data Penelitian, 2018]

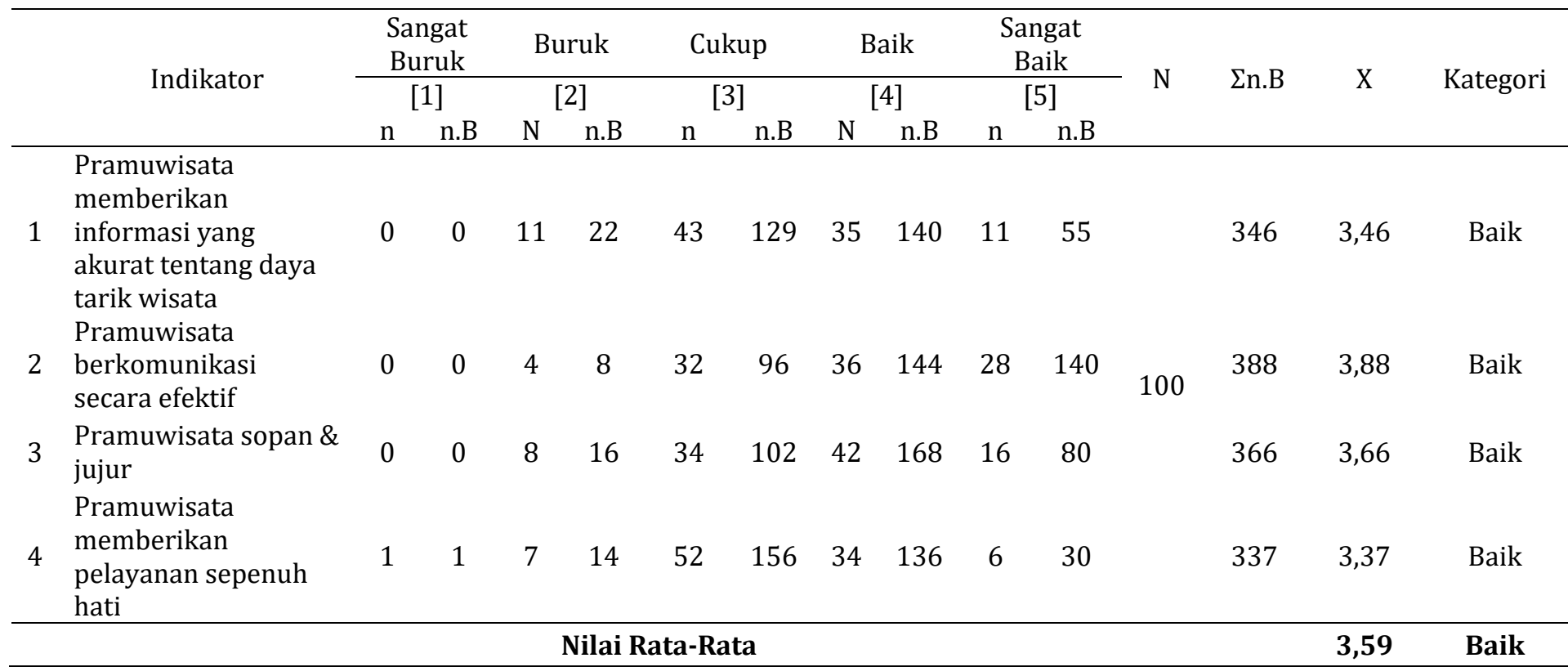

\subsection{Persepsi Wisatawan Jerman Terhadap Kualitas Pelayanan Pramuwisata berbahasa Jerman di PT. Asian Trails Indonesia Dimensi Empathy}

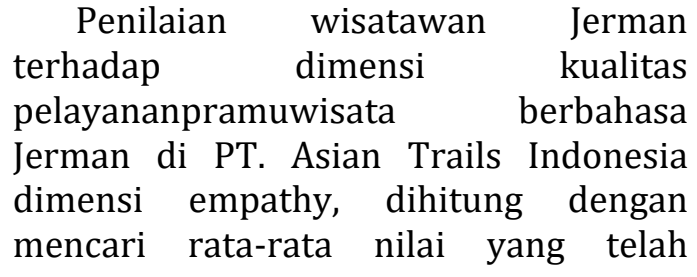


Artajaya, Yanti

didapat dari tanggapan wisatawan Jerman melalui kuesioner. Adapun hasil dari penyebaran 100 kuesioner persepsi wisatawan Jerman yang berlibur di Bali dan menggunakan jasa PT. Asian Trails Indonesia terhadap dimensi empathy, pada tabel sebagai berikut:

Tabel 6 : Hasil Penyebaran 100 Kuesioner Mengunakan Dimensi empathy

[Sumber : Hasil Pengolahan Data Penelitian, 2018]

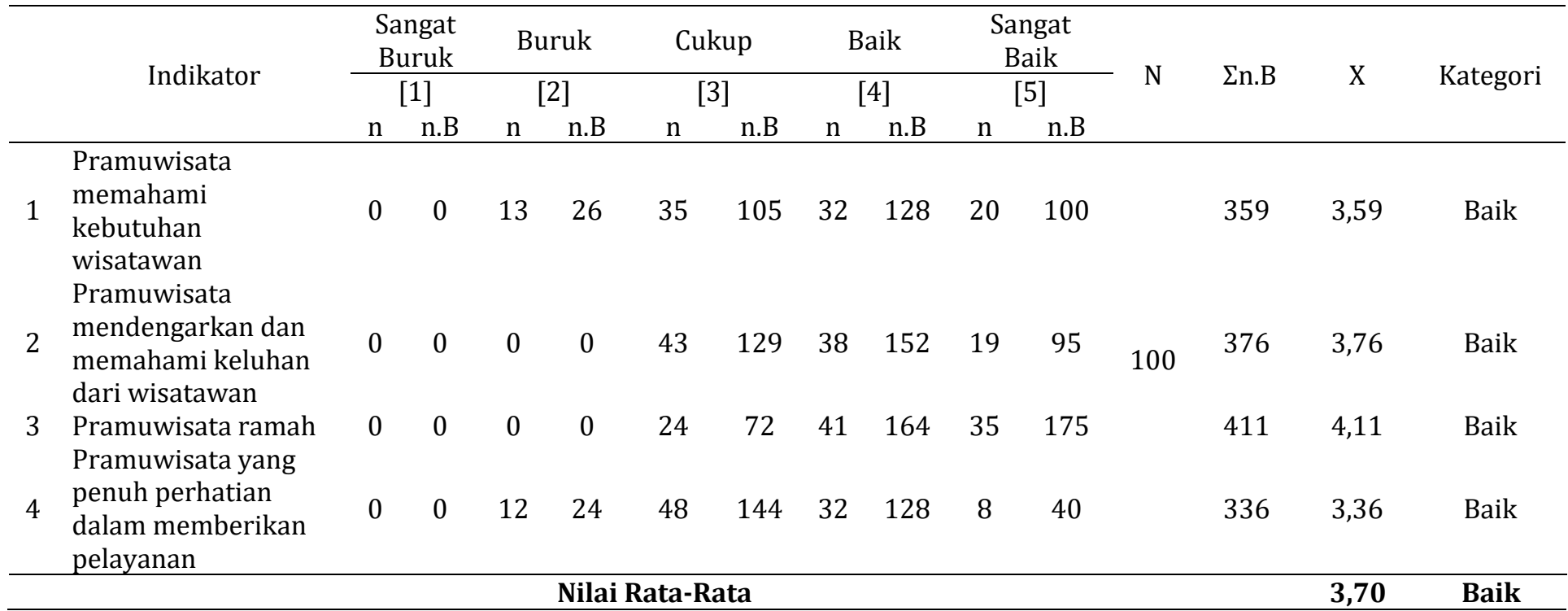

Dari semua skor tersebut diperoleh:

$\frac{3,99+3,67+3,64+3,59+3,70}{5}=3,71$

Dengan demikian, total keseluruhan dari nilai rata-rata kelima aspek tersebut adalah 3,71 yang juga berarti bahwa persepsi wisatawan Jerman terhadap kualitas pelayanan pramuwisata berbahasa Jerman di PT. Asian Trails Indonesia sebagai perusahaan yang bergerak dibidang jasa perjalanan wisata adalah baik.

\section{KESIMPULAN}

Berdasarkan hasil pengolahan data dan pembahasan yang telah diuraikan dapat disimpulkan bahwa persepsi wisatawan Jerman terhadap kwalitas pelayanan pramuwisata berbahasa Jerman masuk dalam kategori baik. Berikut adalah penjabaran hasil persepsi wisatawan Jerman untuk seluruh dimensi kualitas pelayanan. (a) Tangible. Persepsi Wisatawan Jerman menilai bahwa kebersihan seragam pramuwisata, penampilan pramuwisata, kebersihan kendaraan, dan juga kendaraan yang digunakan saat tur maupun transfer sudah dalam kondisi baik dengan nilai rata-rata yang didapatkan yaitu 3,99 yang termasuk dalam kategori baik. (b) Reliability. Pada dimensi reliability wisatawan Jerman memiliki persepsi bahwa pramuwisata berbahasa Jerman masuk pada kategori baik dengan nilai rata-rata 3,67 dalam memberikan informasi yang dibutuhkan tentang daya tarik wisata, pramuwisata sangat membantu wisatawan dan mampu menangani masalah, serta pramuwisata sudah dapat menguasai bahasa Jerman dengan baik. (c) Responsivenesse wisatawan Jerman memiliki persepsi bahwa pramuwisata berbahasa Jerman mendapatkan nilai baik dengan rata-rata 3,64 dalam memberikan informasi mengenai kepastian waktu tur, rela membantu wisatawan, menjalankan permintaan wisatawan dengan tepat dan selalu berusaha memenuhi apa yang 
Artajaya, Yanti

dibutuhkan oleh wisatawan.(d)

Assurance

Second Edition. PT. Raja Grafindo Persada: Jakarta.

Wisatawan Jerman menilai bahwa pramuwisata berbahasa Jerman mampu memberikan informasi yang akurat tentang daya tarik wisata yang dikunjungi, berkomunikasi secara efektif, berlaku sopan dan jujur kepada wisatawan serta menyelesaikan tugasnya dengan baik sehingga wisatawan Jerman memberi nilai ratarata 3,59 yang masuk dalam kategori baik.

(e) Empathy wisatawan Jerman memiliki persepsi terhadap kualitas pelayanan pramuwisata berbahasa Jerman dalam mendengarkan dan memahami keluhan dari wisatawan, memahami kebutuhan wisatawan, penuh perhatian dalam memberikan pelayanan dan bersikap ramah kepada wisatawan dengan nilai rata - rata yaitu 3,70 yang masuk dalam kategori baik.

Berdasarkan hasil penelitian ini, dapat disarankan kepada PT. Asian Trails Indonesia untuk lebih memperhatikan informasi yang disampaikan kepada wisatawan khususnya mengenai daya tarik wisata yang dikunjungi wisatawan, tidak lupa memberikan salam di setiap mulainya perjalanan dan mengucapkan terima kasih serta permohonan maaf di setiap akhir perjalanan wisata, mengedepankan kesopanan agar wisatawan merasa dihargai dan disambut dengan baik, serta meningkatkan komunikasi dan perhatian dengan wisatawan agar apa yang dimaksudkan tersampaikan dengan baik. Selain hal tersebut diharapkan untuk lebih meningkatkan kepekaan, ketepatan pramuwisata dalam memberikan pelayanan juga dalam menangani kejadian-kejadian yang tidak terduga pada saat tour berlangsung.

\section{DAFTAR PUSTAKA}

Parasuraman, A. (1990). Delivering Quality Service. New York: The Free Press.

Foster, Dennis. (2000). First Class an Introduction to Travel and Tourism

Gaspersz, Vincent. (2005). Total Quality Management. Jakarta: Gramedia Pustaka Umum.

Indonesia-Investments, (2017)

Industri Pariwisata Indonesia https://www.indonesia investments.com/id/bisnis/industri -sektor/pariwisata/item6051 Diakses pada 5 Oktober 2017.

Kasmir. (2011). Etika Customer Service. Jakarta: Raja Grafindo Persada.

Kemenpar, (2017), Pertumbuhan Wisatawan Indonesia http://kemenpar.go.id/asp/detil.asp ?c=16\&id=2307 Diakses pada 5 Oktober 2017.

Kotler, P. (2005). Manajemen Pemasaran, Jilid 1. Jakarta: Indeks Kelompok Gramedia.

Kusmayadi dan Sugiarto, E. (2000), Metode Penelitian dalam Bidang Kepariwisataan. Jakarta: PT Gramedia Pusataka Utama.

Muljadi, A.J dan Warman, A. (2014). Kepariwisataan dan Perjalanan. Jakarta: Rajawali Pers.

Sarwono, S. W. (2013). Pengantar Psikologi Umum. Cetakan ke-5. Jakarta: Rajawali Pers.

Slameto. (2010). Belajar dan Faktor Faktor yang Mempengaruhinya. Jakarta: PT. Rineka Cipta.

Sugiyono. 2017. Metode Penelitian Kuantitatif, Kualitatif, dan R\&D. Bandung: Alfabeta.

Sudjana. (2005). Metode Statistika, Bandung: Tarsito.

Suryadana, L \& Octavia, V. (2015). Pengantar Pemasaran Pariwisata. Bandung: Alfabeta.

Supranto, J. (2006) Pengukuran Tingkat Kepuasan Pelanggan untuk Menaikan Pangsa Pasar. Jakarta: Rineka Cipta.

Tjiptono, F. (2006). Manajemen Jasa. Yogyakarta: Andi Offset.

Walgito, Bimo. (2014). Pengantar Psikologi Umum. Yogyakarta: Andi Ofset. 
Artajaya, Yanti

World Federation of Tour Guide Associationhttp://www.wftga.org/t ourist-guiding/what-touristguideDiakses pada 21 Mei 2018.

Yamit, Z. (2004) Manajemen Kualitas Produk dan Jasa. Ekonesia. Yogyakarta: Gramedia Pustaka Utama.

Yoeti, 0. A. (2001). Pemasaran Pariwisata. Bandung: Angkasa. (2001). Tours and Travel Management. Bandung: Angkasa. 